\title{
Teaching nursing students about chronic pain: The lived experience perspective of nurse educators
}

\author{
Moniaree Parker Jones * \\ College of Nursing, Auburn University Montgomery, Montgomery, Alabama, United States
}

Received: December 17, 2014

Accepted: January 13, 2015 Online Published: January 21, 2015

DOI: $10.5430 /$ jnep.v5n4p19

URL: http://dx.doi.org/10.5430/jnep.v5n4p19

\begin{abstract}
The purpose of this phenomenological study was to explore the meanings and interpret as closely as possible the "lived experiences" of nurse educators who have personally experienced chronic pain in an attempt to better understand how these educators articulate and shape how they teach about chronic pain. Understanding the "lived experiences" of nurse educators can assist in determining how the "lived experience" links and gives voice to the way they teach about chronic pain assessment and management and determine if implications exist for reform in undergraduate nursing curriculum. The findings from this study support the need to challenge educational epistemologies that suggest there is a consistently corresponding relationship between pain scales, objective pain assessment, and preconceived judgments regarding chronic pain assessment and management. Subject matter presented in the classroom needs to focus on understanding the problem, which may not resemble the clinical situation in which nurses function. Instruction should be based on context and experience.
\end{abstract}

Key Words: Lived experience, Chronic pain, Curriculum, Nurse educator

\section{Introduction}

The most beautiful people are those who have known defeat, known suffering, known struggle, known loss, and have found their way out of the depths. These persons have an appreciation, sensitivity, and an understanding of life that fills them with compassion, gentleness, and a deep loving concern. Beautiful people do not just happen. God whispers to us in our pleasures, speaks to us in our conscious, but shouts to us in our pains: "It is His megaphone to rouse a deaf world". [1]

The purpose of this study was to explore the meanings and interpret as closely as possible the "lived experiences" of nurse educators who have personally experienced chronic pain in an attempt to better understand how these educators articulate and shape how they teach about chronic pain. Understanding the "lived experiences" of nurse educators can assist in determining how the "lived experience" links and gives voice to the way they teach about chronic pain assessment and management and determine if implications exist for reform in undergraduate nursing curriculum. For the purposes of this study, nursing faculty was defined as any graduate prepared instructor of nursing with a master's degree and/or higher, who have experienced chronic pain and who are employed by an Alabama Board of Nursing approved Registered Nurse program.

\subsection{Learning about chronic pain from nurse educa- tors}

Phenomenology was both the philosophical perspective, as well as, the methodology of this study. An understanding of what the "lived experience" of chronic pain is like for nurse educators contributes to the body of nursing knowledge. Exploration of the lived experience is best suited by a phenomenological approach such as Benner's (1994) ${ }^{[2]}$ Interpretive Phenomenology: Embodiment, Caring, and Ethics in Health and Illness and van Manen's (1990) ${ }^{[3]}$ hermeneutical phenomenological reflection in Researching Lived Ex-

\footnotetext{
* Correspondence: Moniaree Parker Jones; Email: rjones58@aum.edu; Address: College of Nursing, Auburn University Montgomery, Montgomery, United States.
} 
perience: Human Science for an Action Sensitive Pedagogy. The nursing literature lacks studies that explore the qualitative aspects of nurse educators' experiences as they relate to chronic pain and how nurse educators with personal lived experience with chronic pain might articulate or shape pain assessment.

Max van Manen (1990) ${ }^{[3]}$ recognized that the person cannot reflect on the lived experience at the time it is occurring; therefore, reflection is not immediate, but retrospective. A person lives in the moment and experiences specific emotions within the moment. The exact meaning derived from the moment's experience does not become known until reflection occurs. The quality of pain care delivery in the United States continues to fall remarkably short of the potential for optimal care. Pain medicine remains fragmented and without a unified organizational pain model. These consequences of fragmented care threaten patient safety and well-being. Effective pain treatment requires the highest level of clinical reasoning, coordination of medical skills, and strategic use of resources using medical expertise. ${ }^{[4]}$

\subsection{Purpose of the study}

The purpose of this study was to explore the meanings and interpret as closely as possible the "lived experiences" of nurse educators who have personally experienced chronic pain in an attempt to better understand how these educators articulate and shape how they teach about chronic pain. Understanding the "lived experiences" of nurse educators can assist in determining how the "lived experience" links and gives voice to the way they teach about chronic pain assessment and management and determine if implications exist for reform in undergraduate nursing curriculum. There was one broad research question for this study. In what ways does the lived experience with chronic pain shape how a nurse educator understands and engages with pain assessment? Additional focused questions follow: (1) How do nurse educators who have the lived experience with chronic pain theorize or understand chronic pain? (2) How can the lived experience relate to how pain is taught by these individuals and what are the prescribed methods of teaching assessment where nurse educators teach and how does it fit into the nursing curriculum?

\section{Method}

The specific methodology that guided the data collection, analysis, and report writing was interpretive using the phenomenological works of Benner (1994) $)^{[2]}$ and van Manen (1990). ${ }^{[3]}$ Nine purposeful interviews were completed with three nurse educators who had personally experienced chronic pain. The participants met the inclusion-exclusion criteria which included nursing faculty with a master's degree in nursing and who may also have possessed a degree in nursing or a related field beyond the master's degree, who taught full-time, and who lived in the United States. The researcher knew that saturation had been reached when each additional interviewee added little to nothing to what was learned. According to Polit and Beck (2008), ${ }^{[5]}$ there are no rules for sample size in qualitative research. Sample size is largely a function of the purpose of the inquiry, the quality of the informants, and the type of sampling strategy used. Qualitative study sample sizes should be determined based on informational needs; hence a guiding principle in sampling is data saturation that is to the point at which no new information is obtained and redundancy is achieved.

\subsection{Definitions}

Nurse faculty are nurses licensed as a professional nurse with a minimum of a master's degree in nursing and may possess a further graduate degree in nursing or a related field, and who are current instructors in schools of nursing either accredited by the National League for Nursing Accrediting Commission or the Commission on Collegiate Nursing Education. The participants used in this study had personally experienced chronic pain. Chronic pain refers to persistent pain where pain signals keep firing in the nervous system for weeks, months, even years (National Institute of Neurological Disorders and Stroke. ${ }^{[6]}$

The International Association for the Study of Pain defines chronic pain as an unpleasant sensory and emotional experience associated with actual or potential tissue damage. The precise definition of chronic pain is debatable; however, sources agree that chronic pain typically lasts 6 or more months and can be classified according to its origin. ${ }^{[7]}$

\subsection{Procedure/Setting}

Each interview was audio-recorded by the researcher in a mutually agreed upon location and later confidentially transcribed by the researcher for coding. Field notes were used and informed consent was obtained from all participants prior to the interviews.

The first interview focused on the life history of the participant. The second interview concentrated on the details of the participant's experience(s) with pain. The third interview asked participants to reflect on the meaning of their experience and to look at how factors in their lives interact to bring meaning. Ongoing data analysis occurred throughout the process of all three interviews allowing for impact on subsequent interviews.

\subsection{Data collection and analysis}

The participants met the inclusion-exclusion criteria and had the lived experience of chronic pain themselves. Only fulltime nursing faculty were selected to participate in the study. The educators were recruited by sending a formal letter to the President of the Alabama League for Nursing who in turn distributed the recruitment information. 
The Colaizzi method for qualitative data analysis was utilized to help ensure validity. ${ }^{[5]}$ The seven-step process was utilized to maintain uniformity. The researcher then determined if the themes were essential or incidental by looking at the data as a whole. Credibility, dependability, confirmability, and transferability, as identified by Colaizzi, ${ }^{[5]}$ were utilized to ensure trustworthiness. This method includes the following:

- Reading all protocols to acquire a feeling for them

- Reviewing each protocol to extract significant statements

- Spelling out the meaning of each significant statement (i.e., formatting meanings)

- Organizing the formulated meanings into clusters of themes. (A) Refer these clusters back to the original protocols to validate them. (B) Note discrepancies among or between the various clusters, avoiding the temptation of ignoring data or themes that do not fit

- Integrating results into an exhaustive description of the phenomenon under study

- Formulating an exhaustive description of the phenomenon under study with an unequivocal statement of identification as possible

- Asking participants about the findings thus far, as a final validating step
Information was transcribed verbatim from audio recordings of interviews. The text was analyzed for recurring ideas in the statements, phrases, and/or themes that captured the nature and core of the experiences described and was ongoing throughout the interview process based upon the process described by van Manen (1990). ${ }^{[3]}$ Each theme was allocated a color-matched number during coding of information. This part of the procedure required considerable time, as coding is an interactive process (i.e., the researcher coded and recoded as the scheme developed). Once the coding was matched to the transcripts, an attempt was made to interpret their meaning in the context in which they appeared. The interviewer asked the participants to confirm the right interpretation of what they said, which added credibility to the validity and reliability of the results. ${ }^{[8]}$

The data generally flowed into categories. The researcher moved back and forth making notes through journaling for an audit trail, color-coding the text for common themes and essences, and utilizing Nvivo $10^{\mathrm{TM}}$ software to assist in categorizing nodes found in the interview texts. The researcher then determined if the themes were essential or incidental by looking at the data as a whole. Credibility, dependability, confirmability, and transferability, as identified by Colaizzi, ${ }^{[5]}$ were utilized to ensure trustworthiness.

Table 1: Demographic Data for Participants

\begin{tabular}{llll}
\hline & Participant A & Participant B & Participant C \\
\hline Age Range in years & $>35$ & $>35$ & $>35$ \\
Race & Caucasian & Caucasian & Caucasian \\
Highest degree & MSN & MSN & PhD \\
Number of years in nursing & 23 & 31 & 25 \\
Nurse educator years of teaching & 16 & 18 & 8 mos. 12 \\
Courses taught & Fundamentals/Med/Surg & OB/Med/Surg/Leadership Community Health & Med/Surg \\
Type of chronic pain & Rheumatoid arthritis & & Fibroid \\
Years of chronic Pain & Psoriatic arthritis with severe dermatitis & Chronic back pain & tumors/cancer \\
\hline
\end{tabular}

\section{Results}

Using the broad and focused research question as a guide, the researcher carefully analyzed and reviewed the transcripts of three participants for emergent themes, totaling nine interviews. Five major themes emerged, paralleled, and assisted to answer the questions with two subthemes (see Table 2).

\subsection{Chronic pain defined}

The participants defined chronic pain in a variety of ways: Pain that you have off and on like a headache, pain that is not relieved, pain that is there but is never completely gone, unresolved pain, or pain lasting longer than 6 months. Each of the participants expressed that chronic pain is misunderstood by members of the healthcare system and by society in general.

\subsection{Themes}

In the interviews, each of the three participants responded to open-ended questions with five essential themes emerging (see Table 1): vulnerability (mentioned 67 times), coping (mentioned 64 times), physician/provider trust (mentioned 52 times), fear of disability (mentioned 47 times), and need for pedagogical discourse (mentioned 34 times). Two subthemes also emerged: stoic (mentioned 17 times) and "alien" (mentioned in some form by each participant). 
Table 2: Themes

\begin{tabular}{|c|c|}
\hline Themes & Meaning \\
\hline Vulnerability & $\begin{array}{l}\text { desperate, embarrassed, ashamed, crying, inferiority, hopelessness, loss of joy, disbelief, } \\
\text { Subtheme: stoic }\end{array}$ \\
\hline Physician/Provider Trust & poor assessment, drug seeker mentality, questioning, not listening \\
\hline Fear of Disability & $\begin{array}{l}\text { desire to be "normal”, need for independence, betrayed by body, } \\
\text { dependent, loss of socialization, disappointing family, difficulties with activities of daily living, } \\
\text { Subtheme: alien }\end{array}$ \\
\hline Coping & self-realization, adaptation, understanding, reflection, accommodation \\
\hline $\begin{array}{l}\text { Need for Pedagogical } \\
\text { Discourse }\end{array}$ & $\begin{array}{l}\text { lack of adequate teaching hours, poorly written texts, need for better chronic pain assessments, } \\
\text { need for more psychosocial content }\end{array}$ \\
\hline
\end{tabular}

\subsection{Broad research question}

In what ways does the "lived experience" with chronic pain shape how a nurse educator understands and engages with pain assessment? Participants linked their personal descriptions of the phenomenon of living with chronic pain in their conversations and synthesized with one another in the explanatory accounts of their lived reality. The participants gave definitions of chronic pain using descriptive words of the phenomenon representing their understanding of chronic pain. The descriptive definitions included the phrases "pain that does not go away", "pain that stops your activities of daily living", "unresolved pain that keeps coming back", "pain lasting longer than six months", "pain that stops you in your tracks daily", and "pain you can't truly describe to anyone". The participants' definitions are also in keeping with the famous definition by McCaffery (1968) $)^{[9]}$ as "whatever the experiencing person says it is, existing whenever he says it does". ${ }^{[10]}$

\subsubsection{Vulnerability}

Each participant described significant vulnerable experiences encountered by healthcare professionals, some outsiders, and family members related to vulnerability such as feeling desperate, feeling embarrassed, feeling ashamed, crying, feelings of inferiority, hopelessness, loss of joy, and disbelief in their own illness. The subjective experience of being weakened mentally and emotionally regarding one's own level of individual and psychological wellbeing can lead to a kind of vulnerability or demoralization.

Several common features such as vulnerability, coping, and fear of disability were found in other phenomenological studies of the lived experience. In a study by Yeung et al. (2012) ${ }^{[11]}$ two factors, vulnerability and resilience, were shown to influence adaptation to chronic pain. The ability to expand resilient capacities, such as staying attuned to others' emotions, building of social bonds, and improving communication and trust appeared to encourage or promote resilient functioning. Patients who exhibit resilient behaviors tend to have better pain adaptation. Through the words and phrases of the participants, it is evident that their understanding and sense of vulnerability is present as it relates to the chronic pain experience.

Participants spoke about the fear of what they know as nurses concerning chronic pain and disease processes. Each one of the participants spoke about the adjustments that are required when dealing with the chronic condition of pain. Despite a lack of validation at times by others, resilience and the willingness to be open to vulnerability is clearly evident as they cultivate wisdom, fortitude, and insight into living with chronic pain. These rich descriptions capture the ambiguity and complexity of the chronic pain as discussed in the early literature. ${ }^{[12]}$

Each of the participants in this study identified ways they incorporate social resilience to avoid some of the vulnerability they feel. Some of these ways included having a stoic attitude and handling things with prayer, trying to figure out ways to manage the pain such as, topical medication, the importance in staying positive, adapting to travel by making excuses such as "I'll sit here with the baby", and adapting to the activities of daily living such as wearing elastic pants because of the inability to zip or button. The information identified in this study mirrors that by Lindseth and Norberg (2004) ${ }^{[13]}$ who said it is the interpretation integrated into the world which allows knowledge gained to be productive in human life and used to improve care.

In the thematic breakdown, each of the participants indicated feeling on multiple occasions desperate, embarrassed, ashamed, inferior, hopeless, had cried on occasion, and displayed at times a loss of joy as well as disbelief. One of the participants illustrated this when she said,

It was honors night for the students and I had to wear a brace. I got home to get dressed and I could not get dressed. I could not zip my pants or anything. So I changed, put a dress on, and I put on the brace that just immobilizes so I could go because I had to speak at honors night. It bothered me because it was embarrassing to have to wear it. No big black brace is attractive. (Participant A, Interview II, ADN instructor)

Participant B described her vulnerability manifested in 
tears, shame, and inferiority by telling about an encounter she had during a time when her hands were cracking and bleeding from the psoriasis.

When I say things, I'm very calm with it. If I'm upset or anything, I don't let them see the emotion behind it. So particularly on one visit to the physician, I had some psychological issues to discuss because it was beginning to affect me when I would hand money to someone when I'm shopping. I have had them [store clerk] draw back when they see my hands and it had upset me. That had happened the day before. So when I went for my scheduled appointment I tried to tell her about it. It started out very well but then I lost my little composure in my front and I started crying. That was the first time I let her see my emotion. (Participant B, Interview I, ADN instructor)

Subtheme: Stoic. The individuals in this study worried about the vulnerability of everyday life. Lundman and Jansson, (2007) ${ }^{[13]}$ confirmed this in a study about the meaning of living with a long-term disease. The study showed that the main cause of worry in long-term disease was not the disease, but rather its consequences in everyday life. The results revealed a high priority given to values such as working, taking care of oneself, and independence. This is in keeping with the subtheme stoic. Each of the participants voiced the importance of doing what they love to do, which is to teach and give their best to the students they instruct. Like many individuals, having this stoic attitude helps with personal security that the chronic pain threatens.

Each of the study participants spoke about the importance of moving on with their chronic pain. This included the need to look for alternative ways to function, learning to deal with it, and not being a quitter. Challenges in pain assessment need to be acknowledged by healthcare professionals, as well as the need for empowerment in order to promote self-protection of the individual. Until these stories are heard, clinics will remain tense places and individuals will remain unheard. Pain is a subjective experience in which healthcare professionals must refrain from basing their assessment, management, and interventions on personal beliefs and judgments. Sensitivity and empathy are critical components of understanding and learning about chronic pain. ${ }^{[14]}$

There is a tradition within nursing that sees stoicism as a virtue. The nurse educators in this study spoke about the need to "learn to deal with it" or "suck it up (pain) and go on", "I have gotten good at hiding it," and "I have accepted the need to accommodate the pain."

Personality features such as optimism are potential resilience resources. Optimism has been associated with lower ratings of pain. This underscores the importance of incorporating social resilience into the development of interventions to promote adaptive behaviors contributing to stoic type behaviors. ${ }^{[11]}$

\subsubsection{Physician/Provider trust}

The accuracy of pain assessments has received considerable empirical attention. Across a wide range of conditions and settings, nurses often underestimate pain compared to patient self- report. Many reasons likely exist for these discrepancies, including provider bias and lack of insight into the decision-making processes. In a study by Hirsh, Jensen, and Robinson (2010), ${ }^{[15]}$ biases related to patient sex, race, and age appeared to be prominent in practitioner decision making about pain assessment and treatment. The providers in their study appeared to have minimal awareness of bias as indicated by the lack of correspondence between statistical and self-report data.

The study participants indicated that healthcare providers do not always seem to have an in-depth understanding of chronic pain. The participants' spoke of the need for the nurse to enter into the life-world of the patient through dialogue with an exploration of the lived experience. Empathetic listening to the chronic pain patient's concerns, including spirituality, is essential in promoting encouragement and resilience. Participant B said,

So, I've gotten very good at blocking . . . the back pain. And I would find that I would hurt in my jaws because I would clinch. . . . Maybe this is something that I'm expected to have to just tolerate. You know, maybe other people deal with this and don't have to have pain medication. So maybe I'm just being a wuss, and I need to just toughen up.

Participant $\mathrm{C}$ also said,

Because that's one of my biggest fears, what if I'm somewhere and I cannot get out and get any help. Cause it's so stupid, but you don't want to make a spectacle of yourself by, like, fainting in front of a crowd or something like that . . . I very seldom talk to my students about my personal pain.

All three participants in this study spoke about physician/provider trust issues of concern. One of the participants said she was treated differently for pain when compared to her husband. Both of them had visited the same physician only a few days apart for what appeared to be a spider bite. Her husband was given pain medication and she was not, even though her bite was around her waist where her clothes touched the area and her husband's bite was on his chin. 
Another participant spoke about changing physicians several times because she did not feel she was being listened to concerning her condition. This participant had witnessed a treating physician being kind to other patients who were being seen in her town after hurricane Katrina. This witness to the kindness shown by the provider caused her to change over in order to receive the trust that she was going to get the care she deserved. A third participant felt her condition was not taken seriously and being brushed aside as minor. This participant changed providers only to be hospitalized a few days later when she was found to have ovarian cancer. All three of the study participants spoke about physician disbelief related to the need to prescribe pain medications and the emotional distress related to not being heard by the physician. The invisibility of pain is possibly the central problem that chronic pain patients face and it is an aspect that affects the identity of the individual. Newton et al. $(2010)^{[16]}$ explored the phenomenon that chronic pain patients and their experience of being believed is often alluded to in the literature. One participant reflected on her physician visit, her pain assessment and her feelings of being almost invisible,

Combined with this last phone call, I am going to change GYN's because the more I got to thinking after I got home, you know, he did not offer me so much as a Tylenol! He did not explain to me he was doing a biopsy. I had to figure that out when I heard him tell the nurse to get him an EBS kit. I'm thinking EBS kit, Oh! Holy Moly! He's doing a biopsy right now! About that time you know, you feel it. I thought well, so much for that big explanation! And when he said oh, you nurses are so brave I thought . . . so you've had one of these done? I didn't appreciate that at all. (Participant C Interview II, BSN instructor)

Participant $\mathrm{C}$ continued with more about poor assessment saying,

You know it is kind of like the fifth vital sign and whatever your patient says it is. This really hit home with me. You know, trying to do all the classic things of trying to describe it appropriately. What was so interesting is trying to do all the right things and right ways you wish somebody would describe and he picked up on his one thing he wanted to know . . . who referred me? I said, well the clinic at the college where I work because there is where I presented with pain. So I'm going to describe my symptoms and he asks me what I do there. Oh well, I teach. And I thought, who cares? What difference does it make if I collect garbage there. So, that is how he found out I was a nurse. His main concern seemed after that that he might be giving too much information out to me. (Participant $\mathrm{C}$, Interview II, BSN instructor)

\subsection{Fear of disability}

All three participants spoke about their fear of disability. All three participants said that the inability to perform the activities of daily living (ADL's) was a major concern.

Fear of loss of the ability to function socially and fear of disappointing the family were anxiety provoking factors. All three participants talked about the inability to function due to pain and implications for job loss. Fear of relapse during periods of remission was another concern. They spoke about the elevation of fear when a sudden onset or exacerbation with their chronic pain occurs such as not being able to open a can or bottle top, dress one's self, walk in shoes due to friction, or being caught without pain medication. The participants suffer in silence regarding their inabilities and hold to secrecy for the most part.

Participant A described her first encounters with feeling disabled when she said,

Sometimes I couldn't put my bra on. My husband had to help me. Then it would go away. After I had my last child ... right before I had her, I got to where I had a knee, they said I pulled a tendon. They were not sure. I went ahead and got a cortisone injection because I was pretty far along. I couldn't walk, couldn't get off the commode, that kind of stuff. I couldn't raise my arms ... you heard it pop and then one day I couldn't raise it. I thought, oh I pulled it but nothing that would lead you to it because it was on one side. And then it was my knees. I thought I pulled it going up and down the stairs in the auditorium. I didn't know what I'd done. You know, it's like you sit down on the commode, like I talk about in Fundamentals class. You don't think about not being able to move and do simple things. I couldn't get off the commode. You had to pull yourself up. I couldn't squat; if I was on the floor wrapping presents, I'd have to roll to get up. Then I got the cortisone injection, I got a little bit better. (Participant A, Interview I ADN instructor)

In speaking about the future she said,

As far as the future or present, just the same thing, that I can continue to take the medicine. That I won't be able to do anything, I mean that's the fear. I won't be able to move because it's a different pain than acute pain. It just aches 
all the time. (Participant A, Interview 1, ADN instructor)

The participants in this study experienced difficulty with symptom relief with the most difficult periods at the beginning of their diagnostic process. One participant could not get three out of four physicians to prescribe something for her pain. She suffers from severe psoriatic psoriasis with bleeding and cracking lesions of the hands and feet. Her job requires that she instruct students to draw up medication in a syringe using tactile hand movements and to wash her hands frequently. The participant found ways to do her job. She carried gloves and band-aids in her lab coat pocket in order to cover her painful and bleeding fingers. This attempt to compensate for the results of her disease process offered her hope to continue to do her job duties. The healthcare provider had not given her options, so she developed her own methods for coping. Finding ways to compensate and improve symptoms offers hope to situations leading to fear of disability.

Subtheme: "Alien" (feeling as though something foreign has become housed in the body or that something has taken up residence). The chronic pain discussion of the three participants took on a personification role. Participant A stated that her arms and hands feel like "clubs". Participant B referred to her pain as an "organism" or "creature." Participant C said, It's like a separate compartment with an "alien" living inside you. It is almost like it's somebody else's body. The thing is, what the heck is this that's going on in here? And, why is this so difficult to figure out? It is the helplessness, the feeling that your body has betrayed you. Reflecting on the words of the participants leads to the belief that the terms "alien" and "creature" are the internal human reasoning of the participants speaking out to say, "I want you out or I am going to have to accept you!" Participant $C$ gave her fibroid a name. She called it "Phil the Fibroid."

I have gotten used to Phil sitting over here, you know? I'm kind of okay with it. Now if Phil chooses to shrink up to a little peapod, we are good with that. If he chooses to die, that's it; we are not even going to give Phil a funeral!

\section{Participant C stated,}

The helplessness, the feeling of, that initial feeling that your body has betrayed you, that thing, where that's your first thought. It's like it's almost somebody else's body. The thing of, what the heck is this that's going on in here? And why is this so difficult to figure out. What kinds of things are you going to have to do to accommodate this? Because it's almost like it's this whole separate little compartment that lives inside of you and you are having to do all this stuff to kind of accommodate this thing that has taken up residence there. It's sort of like having a little alien up in there. It's sort of like you are having to rest more, change the way you eat, and there are all kinds of things. (Participant $\mathrm{C}$, Interview III, BSN instructor)

\subsubsection{Coping}

The meaning of coping expressed by the participants seems to be linked to self-realization, adaptation, understanding, reflection and accommodation. Coping manifested with the participants in many ways, such as adaptation to the activities of daily living, understanding not to let pain get out of control, toleration of pain at times, understanding the importance of a positive attitude, finding ways to deal with the pain, acknowledging the pain, acceptance of the pain, and understanding that pain is a warning signal. Retaining a sense of control in chronic pain challenges the learning to live with pain and the ability to cope with the unpredictability and incurability of the pain. There is a challenge to find meaning in the suffering, create personal space, be selfprotective, and keep a positive self-image and self-esteem while trying to live a "normal life". ${ }^{17]}$

Participant B explained about coping, accommodation, and adaptation when she said,

When we go on family trips, I don't want to be the one that causes the family not to get to do something or they feel bad because they had to leave me behind. So, many times, I will think, Okay, where are we going? Where could I sit and be a part of this but not have to walk as much? Because of the pain in my feet and my husband's had to take on a different role. Which is strange because I see myself as the caregiver and the helper. The one that, you know, makes things work smoothly. And now he's had to come around to thinking, Okay. I'm going to be out of town, what do I need to do for these days? Because he's not coming back and he will see that I haven't been able to do certain things or get things. One of the things that is funny is just drinks. To open the top of drinks. He will come back and I'll still have all the drinks in the refrigerator and he knows how much I enjoy them. He says, "why did you not, you know they're cold. I put them in there" and I'm ... um, I couldn't open them. That's very frustrating. And you know to put my clothes on, I had to change the way I dressed because I needed elastic. Can't zip or button. (Participant $\mathrm{B}$, Interview II, ADN instructor)

Each of the participants in this study had a tremendous de- 
sire to continue to work and not become disabled. Each indicated that they saw themselves in the future teaching nursing. They represent examples of adapting to a new form of existence, living with chronic pain. Holding on to participation on important arenas seems to be an essential part of successful coping strategies and a caring attitude toward one's body. ${ }^{[12]}$

The participants in this study frequently attempted to alter schedules to lessen the pain debilitation time. One of the participants would still go on family vacations, but stated that she wanted to sit with the grandchild for a while in order to compensate for her tiredness and pain. She felt this made her condition seem less noticeable. She would ask her husband to pre-open the soft drink caps before he left town so she could easily access them while he was gone. Her arthritic condition prevents her from being able to open soft drink cans and bottle caps. Another participant talked about coping by praying on a daily basis. She stated that her pain has actually caused her to trust her faith more.

\subsubsection{Need for pedagogical discourse}

In this study, nurse educators shared stories about their lived experiences with chronic pain and described how they teach about pain in the classroom and clinical setting. One educator recalled a time earlier in her career when she first learned about a chronic pain condition called fibromyalgia. She stated, "I didn't think as much about pain before. Now I realize the importance. I'm getting paid back for all those people I didn't believe" (Participant I, Interview III). She talked about how the utilization of additional pain assessment techniques, and pain scales are now a part of her lesson plans. She also goes behind the student in clinical to do an assessment on the student's assigned patient in order to grade the student on how well the pain assessment was completed. She emphasized the importance of not letting chronic pain or any type pain get out of control. A frequent quote she used was, "It's not just that patient in that room" (Participant A, Interview III). Shaw and Lee (2010), ${ }^{[18]}$ studying misconceptions about chronic pain held by student nurses across 3 years of undergraduate education, found that student nurses hold misconceptions about adults with chronic pain. The study demonstrated inaccurate understandings in relation to the treatment of pain, specifically the existence of tolerance among patients with chronic nonmalignant pain and the risk of addiction to opioids.

This represents inaccurate knowledge and inappropriate attitudes not addressed, to a substantial degree, during the course of undergraduate education. Chronicity and disability need to be obvious in the curriculum.

Another participant spoke about her desire to be thorough when teaching about pain assessment and management. She teaches students to understand that a pain patient may be more sensitive, frustrated, feel inadequate, or even be an- gry. She frames these additions to her lectures based on her own actions and experience with chronic pain. She feels it is important to teach reassurance on behalf of the patient and to incorporate that the patient is not a burden. Validation of the pain is essential. Speaking about the family role in pain is important for the students to understand. She uses discussion frequently in her classroom and integrates more psychosocial. She is quick to point out that there is a deficit in the psychosocial issues in nursing curricula. She believes that the psychosocial aspect is only touched on in the textbooks, leaving the necessity to teach this up to the nursing instructor.

One of the participants stated, "I feel like I know every patient I have ever had now." She went on to say that teaching the pain scales is not enough. Additional teaching focus needs to be on things describing pain such as, "Is it sharp, is it stabbing, etc.?" We need more of "What have you had to stop or start doing?" "Do you have to accommodate this?" "Are you resting more?" (Participant III, Interview III). She believed pain is a warning signal and tried to bring these areas into her lecture and classroom experiences.

Participant A spoke about time to teach about pain when she said,

There's not adequate time to teach about pain. In the fall, I talk a little bit about it and in the spring when I teach medical surgical class and G.I. symptoms. Over the course of three semesters, I guess I teach about 2 weeks total. I want to say six hours altogether if you are talking about three semesters. It's connected to everything else because everything has pain as a part of it. We are crammed full anyway. I just pull in a lot of pain scales and a lot of different ways that the student can identify pain. But pretty much, we use what we have in the textbook or the assessment sheet. I think because of what happened to me, I try to tie it into a lot more when we do talk about activities of daily living because I teach Fundamentals. We go ... about the pain and how it affects everything. How you know, they don't realize when you go to the restroom and you can't get up. Do you hurt, you know, how does it affect you? What can you do with your ADL's I don't think, before I ever did that because it was just a segment in a book that you had to teach. So, I try to expound upon everything that kind of associates with me. Of course, like the GI stuff I teach, we talk about the pain and everything and what causes this. But I try to put it with what's happened to me. So ... they don't understand it. They don't think about it. I think home health probably did that too. Because I 
would be in the houses and I would see when they were home ...things they would have to do for pain with ADL's or how they walk. Does that make sense? (Participant A, Interview II, ADN instructor)

When asked if there is anything she does different now in how she previously taught about pain one participant said,

Just that I make them do a good pain assessment ...go in-depth with it, where before, you just kind of passed it off. The joke was that this county's worse with more people on drugs because of the doctors. Initially I thought that there were going to be more people wanting drugs, more people wanting pain medicine and you have to do the assessment. I don't think one gave credence to pain a lot unless it was surgical pain or cancer pain. That was the way I learned in school and it is just the whole mindset of people you work with here. I mean they didn't teach you to think that people were drug seekers. It's just pain was not a big thing you learned about. You did your assessment and you did ask about the pain, you learned your pain scale and I remember that picture (pain scale). You learned all that stuff, but they didn't do an in-depth assessment back then. You learned about surgical pain, cancer and childbirth pain. But, it wasn't what it is now where you do a better pain assessment. You still see nurses not assess it as well as they know they should and know what questions to ask. That's what I try to teach to students. In class and clinical ... more in clinical I guess because we have patients right there. We talk about it in class because I have to grade their assessments. We put them on the computer and I make them go back and ask if they did not ask. I am trying to make them understand that the patient is a holistic entity, not just "that patient in that room." When he student is done assessing, I assess the patients and see what they were weak in and see that nothing is left out. When you teach patients to take medicine, you have to teach them that it is important to control chronic pain. All the aspects of pain ... that I didn't do before because it didn't happen to me. So I think, after the fact, just knowing you couldn't go to the bathroom, you know ... get off the commode ... really sticks in my mind. You know, cause I did home health for so long and I did a housing assessment when you are in the house. I don't think I realized how important it is than what I gave credence to ... taking it for granted. We used to talk about fibromyalgia or RA. I was like, God, I don't want fibromyalgia because you can't treat it. Really, you know, we used to kind of make fun of it as to whether it was a true illness or not? I was like, Okay, I'm getting paid back for all those people I didn't believe, I guess when they were really hurting and you couldn't find anything wrong with them. So it makes you think, pain is the holistic part for the patient, you know. Pain controls everything ... you can't learn if you are in pain. I hope that I teach the students how to do a better pain assessment and to realize that part of their role is to do that and not treat it like it's not their role. (Participant A, Interview III, ADN instructor)

Participant B also spoke about barriers that exist to teaching,

I think that there are barriers because, I've seen students go into clinical and hear other nurses at report talking about how much medication or pain medication that patient has taken. I know myself, that when I had my first baby, I would not ask for any pain medication in the postpartum area because I knew how they talked about someone that took medication. "She had every dose she can have and she'll ask you for it before it's due." So, yeah, I think that's been an issue. You know, the students get that when they go to report. They get a prejudice or a bias opinion about someone they've never seen because we nurses talk about it in report. (Participant B, Interview II, ADN instructor)

The results of a study by Dysvik et al. (2011) ${ }^{[19]}$ shed light on important aspects of living with chronic pain. By listening to a patient narrative the total situation can be investigated, which might aid nurses in the quest to reduce pain and strengthen those areas that can lead to a meaningful life.

\subsection{Narrow research sub-question 1}

How do nurse educators who have "lived experience" with chronic pain theorize or understand chronic pain? Frustration was expressed by all of the participants and was related to chronic pain treatment and the disease, itself. Specific issues included appointment response times, not receiving pain medications, ineffective results from physician visits, incorrect diagnoses, and believing they actually had a chronic pain diagnosis.

Feelings of self-consciousness were conveyed by all three participants with respect to physical body changes, attempts to hide their illness, and fear of being viewed as a drug seeker, or lazy. Resultant of being physically ill or undiagnosed, all of the participants experienced sadness. Comments such as, "I knew I was going to have to learn to live 
with it," and "I need to learn to adapt to the pain," reflected the emotional intensity felt by the individuals.

The participants spoke about what they perceived to be the needed role of a healthcare provider or nurse who is caring for the patient with chronic pain. They expressed the desire for the healthcare provider or nurse to encourage the patient to talk about their pain, demonstrate compassion, listen as though they are truly interested in their problem, and offer possible choices in treatment plans. The participants expressed a lack of involvement by healthcare providers during the assessment phase of their chronic pain. The participants remarked, "There is a lack of personalization to the experience," "It's an uncaring attitude of the provider," and "There is a lack of communication." The nurses in this study theorized chronic pain by seeing the lived experience of chronic pain as complex and life changing. Living with chronic pain means understanding days of depression, anger, frustration, fear, and self-consciousness. It is, at times, an emotional "rollercoaster." There is need to retain a sense of control and not give up in spite of the pain. The inability to maintain a sense of control of self and pain and to avoid demoralization is a common chronic pain issue. Empowerment and disempowerment from health professionals greatly influence whether the chronic pain is or is not demoralized (Skuladottir). ${ }^{[17]}$

It is vital to acknowledge that an individual can be resilient in some ways and not in others. For example, one can learn from a challenging experience without fully recovering from it. The nurse educators in this study spoke about the importance of support systems to help with their chronic pain issues. Comments like, "I don't know what I would do if I did not have my husband to help me dress some mornings, especially when I am having a flare-up", "I have a fear of being "needy to others", "I debate to tell, or not to tell about my chronic pain in social situations," and "Sometimes I feel my family doesn't understand" are examples of the importance for resilient responses to stressful events like living with chronic pain. Life difficulties and struggles help to fuel an individual to develop resilience while learning to cope with grief, negative feelings, anger, fear, and depression. The ability to cultivate an inner strength to adapt to changes is necessary to find meaning and rise above personal suffering.

\subsection{Narrow research sub-question 2}

How can the "lived experience" relate to how pain is taught by these individuals? What are the prescribed methods of teaching chronic pain assessment and how does it fit into the nursing curriculum? Each of the participants stated that they do teach about pain differently since experiencing chronic pain personally. The impact on their understanding has allowed them to reflect on how they want to be treated regarding their pain and what they need to add to their teaching plans. It is important to help the student to know that not every patient is a drug seeker and that most are simply trying to find an answer or find someone who will listen. Bias during clinical reporting time at change of shift is a problem. Nurses have been witnessed making judgmental remarks about patients seeking pain medications or patients appearing to hyper inflate their pain symptoms. The importance of teaching students about these types of judgments in the clinical setting is important in order to help them avoid negative mentoring.

The participants acknowledged that it is important to make the material personal in their lectures about chronic pain. When assessing pain it is important to ask things like, "What can you not do with the pain, and what can you do with the pain?" "Do you rest more and are you eating?" Assessment is more than just a pain scale. Each participant stressed the importance of caring and compassion. It is debatable in their opinion about whether you can teach caring and compassion, but it is important to look for ways to assess that the student is caring and compassionate. It is also important to add the psychosocial aspects of pain assessment and pain management to curriculum content. Students need guidance to develop evidence-based practice rather than continue with what we have taught in the past. ${ }^{[18]}$

Participants indicated that their lived experience with chronic pain has affected how they teach about pain in diverse ways. Since their personal experience with chronic pain, each participant said they take more lecture time in class on the topic of chronic pain and on the topic of pain in general. Pain is integrated into the curriculum at all three of the schools represented in this study. Each of the participants expressed the need for more time to teach the subject of pain because they spend only about an hour each time it is taught. Each participant indicated that pain is covered over the course of three or more semesters ranging from Fundamentals class to scattered in the Gastrointestinal, Hematology, and Cardiac modules. There is some variance as to which modules are covering pain; however, the periods and subject matter appear to be similar. Scheduling does not allow for longer than the allotted time. This is because of the amount of material nurse educators are expected to cover prior to routine exams in preparation for students to be ready for the National Council Licensure Exam (NCLEX) upon graduation.

Each of the three participants indicated that pedagogical discourse exists in nursing education as identified by lack of adequate teaching hours, poorly written textbooks, poor chronic pain assessments of patients, and the need for more psychosocial content in nursing curricula. Many of the examples given by the participants related to their personal dealings with chronic pain and their insight into what is missing in the curricula. Through the lived experience, we are led to think about the need to teach in a different way.

The participants talked about the importance of teaching 
students to collect accurate and complete information when doing a pain history. It is necessary to teach the importance of observing, recording the location of pain, the duration, the frequency, the degree of pain, and the characteristics that will help in making the correct choice of effective management of pain.

Findings in a study by Pediaditaki ${ }^{[21]}$ suggested that healthcare providers become more sensitive to patient pain after their own experience of pain. Statements such as, "I now think I know every pain patient I have ever had better," "Now I know fibromyalgia is real," and "I didn't think much about pain before my situation" confirm that pain can be the teacher who will help us to see the human being in a different light with concern, interest, and compassion for care.

The educators in this study pointed out that taking time to assess, looking the patient in the eye, having a caring tone in the voice, showing interest, being cognizant of body language, and being thorough in patient encounters are all things that should be included in teaching student nurses about chronic pain assessment and management. The educators also pointed out that it is important that the teacher assess the student's ability to carry out an assessment that includes these important components. The educator cannot properly assess the student for learning unless the educator can verify in some way that the student has reached the objectives for good pain assessment and management. The teaching objectives are assessed by these nurse educators through observing the patient assessment encounters by the students, going over a student's computerized pain assessment to check for completeness with feedback to the student on the day of clinical, and telling personal stories about the life lived with chronic pain. The participants also use classroom activities such as vignettes that stress the psychosocial aspects of chronic pain, classroom discussion about factors related to the activities of daily living, and the role of stress on chronic pain.

The educator's dilemma is how to include an ever-growing body of essential knowledge in the curriculum that is already full and in a manner that is pedagogically sound. Both the associate degree and baccalaureate nurse educators in this study said chronic pain is taught using an integrated model of curricula where pain is discussed throughout the semesters and included in several different modules of study. For example, pain is included in the fundamental, medical surgical, and obstetrical nursing modules. The extent, to which pain is covered, depends upon several types of curriculum. These are the "operational curriculum" (includes knowledge, skills and attitudes emphasized by faculty in the classroom and clinical setting), the "illegitimate curriculum" (that which is actively taught by the teacher and how its importance is communicated to the student such as caring, compassion, and power), the hidden curriculum (consists of values and beliefs taught through verbal and nonverbal communication by the faculty who may not be

Published by Sciedu Press aware of their expressions, priorities and interactions with students), and the "null curriculum" (the curriculum that is not being taught such as content or skills the faculty think are not critical to the design). ${ }^{[22]}$

Each of the participants estimated that pain in general (includes, acute and chronic pain) is covered in about 10 hours or less total in the ADN and BSN nursing curricula. This is interesting, because the length of ADN and BSN programs differ in semester hours of preparation for graduation. To test the hypothesis that educational deficits are in part responsible for the low priority given to pain management by nurses, a study was conducted to ascertain the pain content in the Common Foundation Program in four branches of nursing courses in England. Results indicate that while child and adult programs cover a wide breadth of topics, pain is covered in 10 hours or less. These results indicate superficial coverage of the pain topic. When the amount of time spent teaching, pain is considered (on average less than 10 hours), it becomes apparent that the teaching may not be in any depth. ${ }^{[20,22,23]}$ Further study is needed regarding the number of hours spent teaching about chronic pain in schools of nursing. Curriculum development is led by, and reflective of, the mission and philosophy of the institution and guided by the community and stakeholders.

\section{Implications for nursing}

As evidenced by the thematic review from this study, there are implications for better instruction, nurse educator training, and nursing curriculum change regarding how chronic pain is taught. Nurse educators and teachers are eternal learners. The unyielding commitment to help students reach their full potential leads us to question how we teach. Teaching is an embedded part of the teacher's identity. Nurse educators must consider how experiences influence the selection of content and pedagogy in the classroom. ${ }^{[24]}$

Pain is experienced by all people through time and has no boundaries. Schools of nursing and other healthcare educational establishments should enrich their curriculum with pain education, using those who have had personal experience of pain to illustrate the importance of empathetic pain management. It would be advantageous to invite expatients who had substantial experiences of pain to demonstrate where the gaps in the system need improving.

Nurse educators in this study were asked about their thoughts, feelings, and knowledge related to chronic pain. Through this study, the researcher added to the body of knowledge about the "lived experience" of chronic pain and implications for how pain is taught in nursing schools.

The research on the "lived experience" of nurse educators with chronic pain filled a gap in the literature regarding how pain is assessed and taught by individuals who have actually had chronic pain. This research is important for nursing 
education, because in order for the problem of poor chronic pain assessment and better nursing instruction, it must first be realized, studied, and brought forward for change. The resultant information is significant because it comes from first-person accounts of nurse educators who have personally had chronic pain. These nurse educators have insight that is evidenced by life itself giving meaning and understanding for educational experiences of pain to illustrate where gaps in the system need improving.

The researcher concluded that nurse educators believe chronic pain is under-assessed, misunderstood, and poorly addressed by medical practitioners and nursing students. This presents a negative impact in patient care. The findings from this study support the need to challenge educational epistemologies that suggest there is a consistently corresponding relationship between pain scales, objective pain assessment, and preconceived judgments regarding chronic pain assessment and management. Deconstructing this way of thinking is important by using interpretive pedagogies, which change our preconceived notions. Subject matter presented in the classroom needs to focus on understanding the problem, which may not resemble the clinical situation in which nurses function. Instruction should be based on context and experience. Nurse educators who use only contentbased instruction tend to underpin the gap between theory and practice. ${ }^{[25]}$

This study shows that the personal experience of chronic pain can enable nurse educators a better way to comprehend the complexity of chronic pain leading to improved holistic approaches to improvement in pain assessment and management. There is a need to ensure that nurses have the knowledge and skills to assess and manage pain effectively. Regular updates about chronic pain and changes in practice are necessary for nurse educators to use in teaching students. Teaching strategies that support adult learning and various other learning styles need to be incorporated in the classroom and clinical experiences of student nurses. There is a need for further research related to classroom teaching methods, learning retention, and transference to the clinical setting.

\section{Limitations of the study}

The study participants were all Caucasian females from a middle-class perspective. Studying a broader range of ethnicities would be helpful and it would be helpful to include male participants in the sample. The study represented two participants from a rural background and only one from a metropolitan orientation. It is noted that all three participants had been diagnosed with chronic pain for less than three years during the interview timeframe. It would be interesting to know if the number of years each participant has suffered with the chronic pain would alter the results such as their willingness to talk about their pain more in front of students.

\section{Recommendations for future research}

The discovery challenge of the lived experience of nurse educators with chronic pain answered many questions, just as it fostered additional questions. Further research is needed that will focus on gender differences in chronic pain assessment and the lived experience. Additional studies regarding provider gender in the assessment of pain might be helpful in eliminating gender bias on the part of the provider and the participant. Two of the three participants were close in age range while one participant was slightly younger. Additional studies to see if age differences might skew the data would be beneficial. Research should be conducted on ways to implement the findings of the lived experience of nurse educators with chronic pain into the nursing curricula. The study's findings may assist with the development of other studies on the structure of nursing curriculum. This could assist in curricula that teaches better chronic pain assessment and management, establishment of a curriculum framework, and the creation of strategies or tools for the classroom. The research revealed a deeper understanding; however, limitations were present and questions remain for further study.

\section{Conflicts of Interest Disclosure}

The author declares that there is no conflict of interest statement.

\section{References}

[1] Lewis, C. S. The problem with pain. London: Harper Collins. 1940.

[2] Benner, P. Interpretive phenomenology: Embodiment, caring and ethics in health and illness. Thousand Oaks, CA: Sage Publications. 1994.

[3] van Manen, M. Researching lived experience: Human science for an action sensitive pedagogy. Albany, NY: State University of New York Press. 1990.

[4] American Academy of Pain Medicine. AAPM facts and figures on pain. 2011. Available from: http://www.painmed.org/patien t/facts.html
[5] Polit, D. F., Beck, C. T. Analyzing qualitative data. In H. Surrena $\&$ H. Kogut (Eds.), Nursing research: Generating and assessing evidence for nursing practice Philadelphia, PA: Lippincott Williams \& Wilkins. 2008.

[6] National Institute of Neurological Disorders and Stroke. NINDS Chronic Pain Information Page. 2011. Available from: http://www.ninds.nih.gov/disosrders/chronic_pain/ chronic_pain.htm

[7] International Association for the Study of Pain. Outline curriculum on pain for schools of nursing. 2006. Available from: http://www.iasp-pain.org/AM/Template.cfm?Sect ion=Home\&Template 
[8] Guba, E., Lincoln Y. Epistemological and methodological bases of naturalistic enquiry. In G. Madaus, M. Scriven, D. Stufflebeam (Eds.), Evaluation models. 1983; 311-339.

[9] McCaffery, M. Nursing practice theories related to cognition, bodily pain, and man-environment interactions. Los Angeles: UCLA Students Store. 1968.

[10] McCaffery, M., Grimm, M. A., Pasero, C., Ferrell, B., Unman, G. C. On the meaning of "drug seeking." Pain Management Nursing. 2005; 6(4): 122-136. PMid:16337561 http://dx.doi.org/10. 1016/j.pmn.2005.08.002

[11] Yeung, E., Arewasikporn, A., Zautra, A. Resilience and chronic pain. Journal of Social and Clinical Psychology. 2012; 31: 593-617. http://dx.doi.org/10.1521/jscp.2012.31.6.593

[12] Raheim, M., Haland, W. Lived experience of chronic pain and fibromyalgia: Women's stories from daily life. Qualitative Health Research. 2006; 16(6): 741-761. PMid:16760533 http://dx.doi.o $\mathrm{rg} / 10.1177 / 1049732306288521$

[13] Lindseth, A., Norberg, A. A phenomenological hermeneutical method for researching lived experience. Scandinavian Journal of Caring Science. 2004; 145-153. PMid:15147477 http://dx.doi .org/10.1111/j.1471-6712.2004.00258.x

[14] AL-Shaer, D., Hill, P. D., Anderson, M. A. Nurses' knowledge and attitudes regarding pain assessment and intervention. Medsurg Nursing. 2011; 20(1): 7-11. PMid:21446289

[15] Hirsh, A., Jensen, M., Robinson, M. Evaluation of nurses' selfinsight into their pain assessment and treatment decisions. The Journal of Pain. 2010; 11(5): 454-461. PMid:20015702 http://dx.d oi.org/10.1016/j.jpain.2009.09.004

[16] Newton, B. J., Southall, J. L., Raphael, J. H., Ashford, R. LL., LeMarchand, K. A narrative review of the impact of disbelief in chronic pain. Pain Management Nursing. 2010; 1-11.

[17] Skuladottir, H., Halldorsdottir, S. Women in chronic pain: Sense of control and encounters with health professionals. Qualitative Health
Research. 2008; 18: 891-901. PMid:18552316 http://dx.doi.o $\mathrm{rg} / 10.1177 / 1049732308318036$

[18] Shaw, S., Lee, A. Student nurses' misconceptions of adults with chronic nonmalignant pain. Pain Management Nursing. 2010; 11(1): 2-14. PMid:20207323 http://dx.doi.org/10.1016/j.pmn.2 008.10 .002

[19] Dysvik, E., Sommerseth, R., Jacobensen, F. Living a meaningful life with chronic painfrom a nursing perspective: Narrative approach to a case story. International Journal of Nursing Practice. 2011; 17: 36-42. PMid:21251152 http://dx.doi.org/10.1111/j.1 440-172X. 2010.01903.x

[20] Pediaditaki, O., Antigoni, F., Theofandis, D. Research on the influence of healthcare professionals' personal experience of pain on the management of pain. International Journal of Caring Sciences. 2010; 3(1): 29-39.

[21] Billings, D. M., Halstead, J. A. Curriculum development: An overview. In N. Dillard \& L. Siktberg (Eds.), Teaching in nursing: A guide for faculty. St. Louis, MS:Saunders. 2009; 79-80.

[22] Twycross, A. Education about pain: A neglected area? Nurse Education Today. 2000; 20(3): 244-253. PMid:10820579 http: //dx.doi.org/10.1054/nedt.1999.0412

[23] Twycross, A. Educating nurses about pain management: The way forward. Journal of Clinical Nursing. 2002; 11: 705-714. PMid:12427174 http://dx.doi.org/10.1046/j.1365-2702. $2002.00677 . \mathrm{x}$

[24] Cone, T. C. In the moment: Honoring the teaching and learning lived experience. Journal of Physical Education, Recreation \& Dance. 2007; 78(4): 35-54. http://dx.doi.org/10.1080/07303084. 2007.10598005

[25] Kantar, L., Alexander, R. Integration of clinical judgment in the nursing curriculum: Challenges and perspectives. Journal of Nursing Education. 2012; 52(8): 444-453. PMid:22694668 http://dx .doi.org/10.3928/01484834-20120615-03 